\title{
Clinical Significance of Tumor Regression Grade in Rectal Cancer with Preoperative Chemoradiotherapy
}

\author{
Young Joo Park, Byung Ryul Oh, Sang Woo Lim, Jung Wook Huh, Jae Kyun Joo, Young Jin Kim, \\ Hyeong Rok Kim \\ Department of Surgery, Chonnam National University Medical School, Gwangju, Korea
}

Purpose: Neoadjuvant chemoradiotherapy applied to the locally advanced rectal cancer reduces local recurrence and improves survival. We assessed tumor regression grade (TRG) and its influence on survival in rectal cancer patients treated with chemoradiotherapy followed by surgical resection.

Methods: We studied 108 patients that were seen at our hospital between August 2004 and December 2008. Patients received preoperative chemoradiotherapy consisting of 5-fluorouracil and leucovorin by continous infusion during the first and fifth week, delivered with concurrent pelvic radiation of $50.4 \mathrm{~Gy}$, followed by radical surgery at 6-8 weeks. The TRG was determined by the amount of fibrosis in the tumor embedding area and was divided into 5 grades based on the relative amount of fibrosis. We analyzed all preoperative clinicopathologic factors, postoperative pathologic stages, TRG and prognosis, retrospectively.

Results: Downstaging of rectal cancer through neoadjuvant chemoradiotherapy occurred in 64 (59\%) patients. The numbers of total regressions (TRG4), good regressions (TRG3), moderate regressions (TRG2), minor regressions (TRG1), and no regression (TRG0) were $19(18 \%), 65(60 \%), 17(16 \%), 6(5 \%)$, and $1(1 \%)$ respectively. The TRG was inversely correlated with perineural invasion and lymphovascular invasion $(\mathrm{P}=0.008, \mathrm{P}=0.032)$. The local recurrence rate declined as the tumor regression grade increased $(\mathrm{P}=0.032)$. The 19 patients with TRG4 had a better three-year disease free survival than the 89 patients with TRG0-3 $(\mathrm{P}=0.034)$. The 16 patients with pathologic complete remission $(\mathrm{pCR})$ had a better three-year disease free survival than the 92 patients with non-pCR $(\mathrm{P}=0.025)$.

Conclusion: Higher TRG after preoperative chemoradiotherapy for rectal cancer closely correlates with better survival and low local recurrence. The TRG is considered to be a significant prognostic factor.

Keywords: Rectal cancer; Tumor regression grade; Preoperative chemoradiotherapy

\section{INTRODUCTION}

Rectal cancer is an increasing disease in South Korea and shows a local recurrence rate of $15-40 \%$ when only surgical treatment is executed [1]. In addition, the local recurrence rate of locally advanced rectal cancer is reported to be $4-27 \%$ after radical

Received: April 14, 2010 Accepted: July 14, 2010

Correspondence to: Hyeong Rok Kim, M.D.

Division of Colorectal Surgery, Department of Surgery, Chonnam National

University Medical School, 8 Hak-dong, Dong-gu, Gwangju 501-746, Korea

Tel: +82-61-379-7643, Fax: +82-61-379-7661

E-mail:drkhr@jnu.ac.kr

(C) 2010 The Korean Society of Coloproctology

This is an open-access article distributed under the terms of the Creative Commons Attribution NonCommercial License (http://creativecommons.org/licenses/by-nc/3.0) which permits unrestricted non-

commercial use, distribution, and reproduction in any medium, provided the original work is properly cited. surgery accompanied by preoperative radiotherapy $[2,3]$. This greatly affects the patients' survival rate, and research to reduce the local recurrence and distant metastases is being done. Especially, preoperative chemoradiotherapy is known to reduce the local recurrence, reduce the tumor size [4], stabilize the tumor margin to increase resectability, increase the anal sphincter conservation rate [5], and reduce tumor metastasis by eliminating local lymph nodes and blocking metastasis routes [6]. The tumor regression grade (TRG) was first introduced by Mandard et al. [7] through a patient with esophageal cancer. The TRG can categorize cancer cell ratio from tissue with fibrosis or inflammation in numerous stages throughout chemoradiotherapy. In addition, Suarez et al. [8] reported that the TRG might be a superior prognostic factor in predicting the survival rather than TN downstaging after preoperative chemoradiotherapy. Berger et al. [9] reported a better disease-free survival 
rate in a pathologic complete remission (pCR) group. HabrGama et al. [10] reported similar treatment results from a clinically CR group with surgical excision and a clinically CR group with only catamnesis observation.

This study measured the TRG for rectal cancer patients who underwent surgery after chemoradiotherapy. The study is intended to guide a future treatment plan for rectal cancer patients by analyzing clinicopathological factors, overall survival rate and disease-free survival rate.

\section{METHODS}

\section{Object of study}

From September 2004 to December 2008, among 142 patients who had chemoradiotherapy before surgery at Chonnam National University Hwasun Hospital, the 108 patients with the exception of patients who did not finish chemoradiotherapy, failed to execute radical excision, failed to measure TRG, had metastasis at diagnosis, or failed to have follow-up observation over 1 year were retrospectively analyzed. Preoperative chemoradiotherapy was executed in patients with rectal cancer located within $10 \mathrm{~cm}$ of the anal verge, and no distant metastasis tumor located near the anal verge in spite of the low stage of the disease.

\section{Methods}

Radiation therapy was executed either as 2-dimensional or 3dimensional conformal therapy by using high-energy X-rays (6 MV or $10 \mathrm{MV}$ ). The daily radiation dose was $180 \mathrm{cGy}, 5$ times a week, for 5 weeks, for a total of 4,500 cGy, with conventional fractionation encompassing the rectum and intrapelvic lymph node. A dose of $540 \mathrm{cGy}$ was added on the primary area and the high risk area after reducing the boost field, projecting a total of 5,040 cGy. Chemotherapy was executed by continuously injecting 5 -fluorouracil (5-FU) $\left(500 \mathrm{mg} / \mathrm{m}^{2} /\right.$ day) and leucovorin $\left(20 \mathrm{mg} / \mathrm{m}^{2}\right)$ during the first and last week of radiotherapy. One round of chemotherapy was done in five days and two rounds were done in total [11].

\section{Diagnosis, postoperative follow-up test, and pathogenesis}

As basic tests before treatment, digital rectal examination, a blood test, a serum carcinoembryonic antigen (CEA), simple

Table 1. Tumor regression grade (TRG) chest X-ray, abdominopelvic CT, pelvic MRI, positron emission tomography (PET), colonoscopy, and biopsy were executed. Tumor shapes were categorized as 'fungating' or 'ulcerative' based on the findings of colonoscopy. Patients with polypoid and ulcerofungating tumor were categorized as the fungating group, and patients with ulceroinfiltrative tumor were categorized as the ulcerative group. Histological categorization was done based on results of colonoscopic biopsy and was recorded as well differentiated, moderately differentiated, and poorly differentiated. Mucinous differentiation was considered as poorly differentiated. Also, perineural invasion and lymphovascular invasion were measured based on the postoperative pathologic findings.

Follow-up examination after surgery was done every 3 months in the first 2 years and every 6 months after that. Categories of examinations were digital rectal examination, laboratory test, serum CEA, chest X-ray and abdominopelvic CT. Chest CT, pelvic MRI, and PET scans were executed based on need. Pathologic stage was done by following the categorization of the 2002 American Joint Committee on Cancer (AJCC), 6th edition.

\section{Surgical treatment}

Surgery was executed 6-8 weeks after chemoradiotherapy had been completed. High ligation and total mesorectal excision (TME) were set as bases in all patients. Great caution was taken during high ligation in order to prevent damaging to the initial segment of the intra-pelvic sympathetic nervous system. A double ligation was executed on the proximal side of the inferior mesenteric artery. Following the visceral layer of the mesorectal fascia and the avascular layer between parietal layers, Waldeyer's fascia was the rear boundary, and Denonvilliers' fascia and peritoneal reflexion were the front boundary where dissection was executed. Dissection was done until the front and the lateral surfaces cross the rear surface. The pelvic nerve was conserved on both lateral surfaces.

\section{Tumor regression grade}

Downstaging was done by comparing pathologic stage after surgery with clinical stage before chemoradiotherapy. The pathologic treatment response was determined by two pathologists re-analyzing pathology slides. The 5-stage system suggested by Dworak et al. [12] was used, and categorization was based on the degree of fibrosis, necrosis, and change in blood vessels (Table 1,

\begin{tabular}{lll}
\hline Grade & No regression & Fibrosis was completely absent \\
\hline TRG0 & Minor regression & Dominant tumor mass with obvious fibrosis in $25 \%$ or less of the tumor mass \\
TRG1 & Moderate regression & Dominant tumor mass with obvious fibrosis in $26 \%$ to $50 \%$ of the tumor mass \\
TRG2 & Good regression & Dominant fibrosis outgrowing the tumor mass; more than $50 \%$ tumor regression \\
TRG3 & Total regression & No viable tumor cells; only fibrotic mass \\
\hline
\end{tabular}



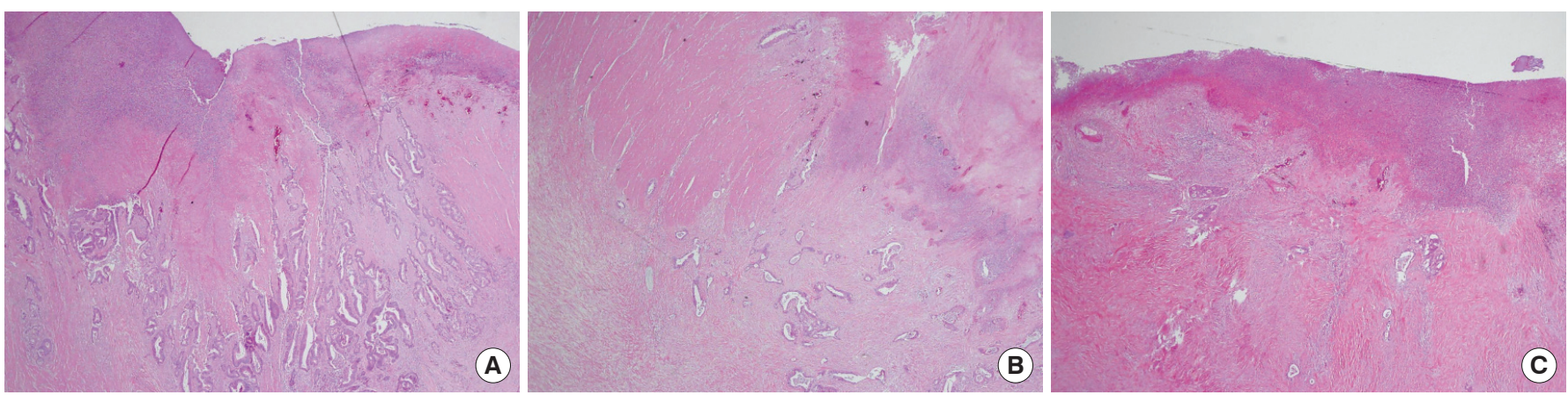

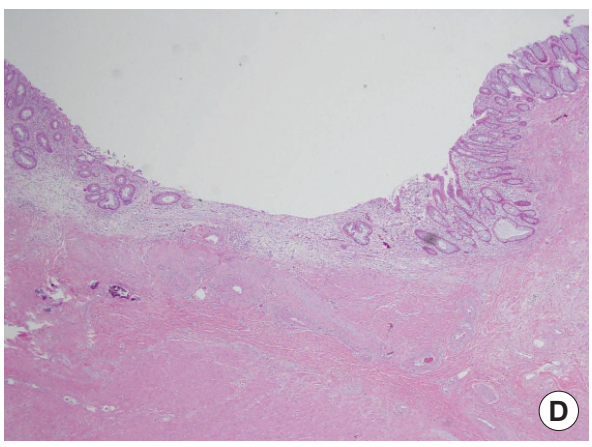

(D)
Fig. 1. Microscopic appearances of rectal tissue. (A) Tumor regression grade 1: minor regression and fibrosis in only $25 \%$ or less of the tumor mass. (B) Tumor regression grade 2: moderate regression, and dominant tumor mass with obvious fibrosis in $26 \%$ to $50 \%$ of the tumor mass. (C) Tumor regression grade 3: good regression and dominant fibrosis outgrowing the tumor mass with more than $50 \%$ tumor regression. (D) Tumor regression grade 4 : total regression, no viable tumor cells, and only fibrotic mass $(\mathrm{H} \& \mathrm{E}, \times 20)$.
Fig. 1) [13]. Pathologic complete remission (pCR) was defined as PTON0, for which the primary site of resected specimen and lymph node did not show tumor cells.

\section{Statistical analysis}

Statistical analysis was done by using SPSS ver. 15.0 (SPSS Inc., Chicago, IL, USA). Frequency difference in each group was checked with a Turkey Post-Hoc test after a one-way layout analysis and a Pearson $\chi^{2}$ test. The survival rates were compared with the Kaplan-Meier method and the log-rank test. When the P-value was less than 0.05 , the result was considered to have statistical significance.

\section{RESULTS}

\section{Patient characteristics}

The subject group had a total of 108 people: 85 male (79\%) and 23 female (21\%). The average age was $59.7 \pm 11.8$ (31-80). Ninety-six patients (89\%) had lower rectal cancer (within $5 \mathrm{~cm}$ from the anal verge) and 12 patients (11\%) had mid-rectal cancer (within $10 \mathrm{~cm}$ from the anal verge). The histological categorizations were 43 well differentiated (40\%), 57 moderately differentiated (53\%), and 5 poorly differentiated (5\%), and 86 patients (80\%) had a fungating tumor. Clinical stage before concurrent chemoradiotherapy (CCRT) was 8 stage I (7\%), 33 stage II (31\%), and 67 stage III (62\%).

\section{Surgical treatment and complications}

Among the 108 patients who had surgery after CCRT execution, $84(78 \%)$ had laparoscopic surgery, and types of surgery
Table 2. Type of surgery after preoperative chemoradiotherapy

\begin{tabular}{lc}
\hline Type of surgery & No. (\%) \\
\hline Low anterior resection & $45(42)$ \\
Abdominoperineal resection & $18(16)$ \\
Intersphincteric resection & $43(40)$ \\
Hartmann's operation & $1(1)$ \\
Subtotal colectomy & $1(1)$ \\
\hline
\end{tabular}

Table 3. Tumor regression grade (TRG) with respect to the primary tumor in 108 patients treated with preoperative chemoradiotherapy and surgery

\begin{tabular}{lc}
\hline TRG & No. (\%) \\
\hline TRG0 & $1(1)$ \\
TRG1 & $6(5)$ \\
TRG2 & $17(16)$ \\
TRG3 & $65(60)$ \\
TRG4 & $19(18)$ \\
Total & 108 \\
\hline
\end{tabular}

are shown in Table 2. One patient who underwent a subtotal colectomy also had a tumor in the rectum and descending colon. As a result, the ascending colon was conserved, and the patient underwent a subtotal colectomy.

As postoperative complications, there were 4 patients with anastomosis leakage (4\%) and 5 patients with intra-pelvic abscess $(5 \%)$. Patients with anastomosis leakage were treated with an ileostomy or T-loop colostomy, and patients with an 
intra-pelvic abscess were treated with antibiotics and external drainage. No patients died because of the surgical treatment.

\section{Preoperative chemoradiotherapy treatment results}

The TRG distribution was 1 TRG0 (1\%), 6 TRG1 (5\%), 17 TRG2 (16\%), 65 TRG3 (60\%) and 19 TRG4 (18\%) (Table 3).
Among the TRG4 patients, 3 showed N (+); one patient among the TRG 3 patients showed Tis and was diagnosed as yp0. In 64 of the 108 patients (59\%), final pathologic stages were reduced through CCRT. But two patients were diagnosed as stage IV. One patient had liver metastasis based on abdominal CT after CCRT, went through a left lateral sectionectomy, and was

Table 4. Comparison between pre-concurrent chemoradiotherapy stage and pathologic stage

\begin{tabular}{|c|c|c|c|c|c|c|c|c|}
\hline \multirow{2}{*}{ Pre-CCRT stage } & \multicolumn{8}{|c|}{ Postoperative pathologic stage } \\
\hline & yp0 & ypl & ypll & ypllIA & ypllIB & yplIIC & yplV & Total \\
\hline I & $1^{\mathrm{a}}$ & 7 & & & & & & 8 \\
\hline$\|$ & $5^{\mathrm{a}}$ & $9^{a}$ & 16 & & 1 & & 2 & 33 \\
\hline 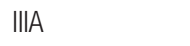 & $2^{\mathrm{a}}$ & & $1^{\mathrm{a}}$ & 1 & & & & 4 \\
\hline IIIB & $7^{\mathrm{a}}$ & $5^{a}$ & $13^{\mathrm{a}}$ & $3^{\mathrm{a}}$ & 8 & 5 & & 41 \\
\hline IIIC & $2^{\mathrm{a}}$ & $1^{\mathrm{a}}$ & $9^{\mathrm{a}}$ & $1^{\mathrm{a}}$ & $5^{\mathrm{a}}$ & 4 & & 22 \\
\hline Total & 17 & 22 & 39 & 5 & 14 & 9 & 2 & 108 \\
\hline
\end{tabular}

CCRT, concurrent chemoradiotherapy.

aDownstaging number.

Table 5. Correlation between tumor regression grade (TRG) and clinicopathologic factors

\begin{tabular}{|c|c|c|c|c|c|}
\hline & TRG0\&1 & TRG2 & TRG3 & TRG4 & P-value \\
\hline Age (yr) & $68.0 \pm 7.87$ & $57.88 \pm 12.12$ & $59.88 \pm 12.33$ & $57.37 \pm 11.81$ & 0.203 \\
\hline $\begin{array}{l}\text { Sex } \\
\text { Male } \\
\text { Female }\end{array}$ & $\begin{array}{l}6(86) \\
1(14)\end{array}$ & $\begin{array}{r}14(82) \\
3(18)\end{array}$ & $\begin{array}{l}49(76) \\
16(24)\end{array}$ & $\begin{array}{r}16(84) \\
3(16)\end{array}$ & 0.794 \\
\hline $\begin{array}{l}\text { Tumor site } \\
\text { Middle }(>5, \geq 10 \mathrm{~cm}) \\
\text { Lower }(\leq 5 \mathrm{~cm})\end{array}$ & $\begin{array}{l}1(14) \\
6(86)\end{array}$ & $\begin{array}{c}0 \\
17(100)\end{array}$ & $\begin{array}{c}6(9) \\
59(91)\end{array}$ & $\begin{array}{r}5(26) \\
14(74)\end{array}$ & 0.073 \\
\hline $\begin{array}{l}\text { Histologic type } \\
\text { Well differentiated } \\
\text { Moderately differentiated } \\
\text { Poorly differentiated } \\
\text { Unknown }\end{array}$ & $\begin{array}{l}4(58) \\
2(28) \\
1(14) \\
0\end{array}$ & $\begin{array}{l}4(24) \\
13(76) \\
0 \\
0\end{array}$ & $\begin{array}{c}28(43) \\
33(50) \\
3(5) \\
1(2)\end{array}$ & $\begin{array}{l}7(37) \\
9(47) \\
1(5) \\
2(11)\end{array}$ & 0.369 \\
\hline $\begin{array}{l}\text { Macroscopic shape } \\
\text { Ulcerative } \\
\text { Fungating }\end{array}$ & $\begin{array}{l}1(14) \\
6(86)\end{array}$ & $\begin{array}{r}4(24) \\
13(76)\end{array}$ & $\begin{array}{l}16(25) \\
49(75)\end{array}$ & $\begin{array}{c}1(5) \\
18(95)\end{array}$ & 0.312 \\
\hline Pre-CCRT CEA (ng/mL) & 7.72 & 10.87 & 11.7 & 4.77 & 0.564 \\
\hline $\begin{array}{l}\text { Pre-CCRT stage } \\
\text { I } \\
\| \\
\text { IIIA } \\
\text { IIIB } \\
\text { IIIC }\end{array}$ & $\begin{array}{l}0 \\
1(14) \\
0 \\
3(43) \\
3(43)\end{array}$ & $\begin{array}{l}2(12) \\
6(35) \\
0 \\
8(47) \\
1(6)\end{array}$ & $\begin{array}{c}5(8) \\
22(33) \\
2(3) \\
22(35) \\
14(21)\end{array}$ & $\begin{array}{l}1(5) \\
4(21) \\
2(11) \\
9(47) \\
3(16)\end{array}$ & 0.553 \\
\hline $\begin{array}{l}\text { Postoperative N stage } \\
\text { ypN0 } \\
\text { ypN1 } \\
\text { ypN2 }\end{array}$ & $\begin{array}{l}2(29) \\
5(71) \\
0\end{array}$ & $\begin{array}{l}13(76) \\
4(24) \\
0\end{array}$ & $\begin{array}{r}49(74) \\
8(13) \\
8(13)\end{array}$ & $\begin{array}{c}16(84) \\
2(11) \\
1(5)\end{array}$ & 0.003 \\
\hline Perineural invasion & $4(58)$ & $7(41)$ & $22(33)$ & 0 & 0.008 \\
\hline Lymphovascular invasion & $2(28)$ & $5(29)$ & $7(11)$ & 0 & 0.032 \\
\hline
\end{tabular}

Values are presented as numbers (\%).

CCRT, concurrent chemoradiotherapy; CEA, carcinoembryonic antigen. 
diagnosed as ypT2N0M1. The other patient was diagnosed as cT3N0 before surgery, but metastasis was found in a lymph node biopsy paraaorta during surgery (Table 4 ).

\section{Group comparison based on TRG}

Based on the TRG, age, sex, location of tumor, histological differentiation, shape of tumor and CEA before CCRT execution were analyzed, and no relationship to the TRG was found. Clinical stage before CCRT did not have a statistically significance relation to the TRG $(\mathrm{P}=0.553)$. Based on the final biopsy results after surgery, the ypN stage was compared between groups. ypN $(+)$ was reduced as TRG increased $(\mathrm{P}=$ $0.003)$. Also, perineural invasion and lymphovascular invasion decreased as TRG increased $(\mathrm{P}=0.008, \mathrm{P}=0.032)$ (Table 5).

The average postsurgical follow-up observation period was 27 months. Local recurrence occurred in 16 patients (15\%): 3 patients (43\%) had TRG0 \& 1, 4 patients (24\%) had TRG2, and 9 patients (14\%) had TRG3. Most recurrence were intra-pelvic recurrence, and local recurrence decreased as the TRG increased ( $\mathrm{P}=0.032)$. Twenty-six patients $(24 \%)$ had distant metastasis, and 17 of those (65\%) had lung metastasis. Lung metastasis was detected in two patients with TRG4 21 months from the surgery, and 1 out of 2 was $\mathrm{N}(+)$ (Table 6).

Overall survivals (OS) for TRG0\&1, TRG2, TRG3, and TRG4 in 3 years were $51 \%, 66 \%, 86 \%$, and $94 \%$, respectively. The threeyear disease-free survival (DFS) rates were $48 \%, 51 \%, 68 \%$, and $76 \%$, respectively. The three-year overall survival and the three- year disease-free survival improved as the TRG increased, but this result was not statistically significant $(P=0.070, P=0.125)$ (Fig. 2).

When comparing the TRG0-3 group and the TRG4 group, the three-year overall survival rates were $78 \%$ and $94 \%$, and the three-year disease-free survival rates were $62 \%$ and $76 \%$, respectively. The TRG4 group showed better OS and DFS rates and showed statistical significance in the three-year DFS (P = 0.034) (Fig. 3). Also, 16 patients in the pathologic complete remission (pCR) group and the non-pCR group showed threeyear OS rates of $93 \%$ and $79 \%$, and three-year DFS rates of $90 \%$ and $60 \%$, respectively. The pCR group showed a better threeyear DFS rate than the non-pCR group, and this difference showed statistical significance $(\mathrm{P}=0.025)$ (Fig. 4).

\section{DISCUSSION}

Preoperative chemoradiotherapy in locally advanced rectal cancer reduces local recurrence, increases operability, and increases the anus conservation rate, ultimately increasing the survival rate. Heald et al. [14] introduced total mesorectal excision, and the local relapse rate was reduced to $7 \%$, and the anal sphincter conservation rate was increased by more than $20 \%$ [15]. From a Swedish rectal cancer trial, the group that underwent radiotherapy after surgery had an increased fiveyear survival rate compared to the group that only had surgery, $58 \%$ compared to $48 \%$ [16]. In other research after that,

Table 6. Tumor recurrence and tumor regression grade (TRG)

\begin{tabular}{lccccc}
\hline & TRG0 \& 1 $(\mathrm{n}=7)$ & TRG2 $(\mathrm{n}=17)$ & TRG3 $(\mathrm{n}=65)$ & TRG4 $(\mathrm{n}=19)$ & Total $(\mathrm{n}=108)$ \\
\hline Local recurrence $^{\mathrm{a}}$ & $3(43)$ & $4(24)$ & $9(14)$ & $0(0)$ & 16 \\
Systemic recurrence $^{\mathrm{b}}$ & $2(29)$ & $5(29)$ & $17(26)$ & $2(11)$ & 26 \\
Both & 2 & 1 & 6 & 0 & 9 \\
\hline
\end{tabular}

Values are presented as number (\%).

aP $=0.032 ;{ }^{\text {b }} \mathrm{P}=0.50$.
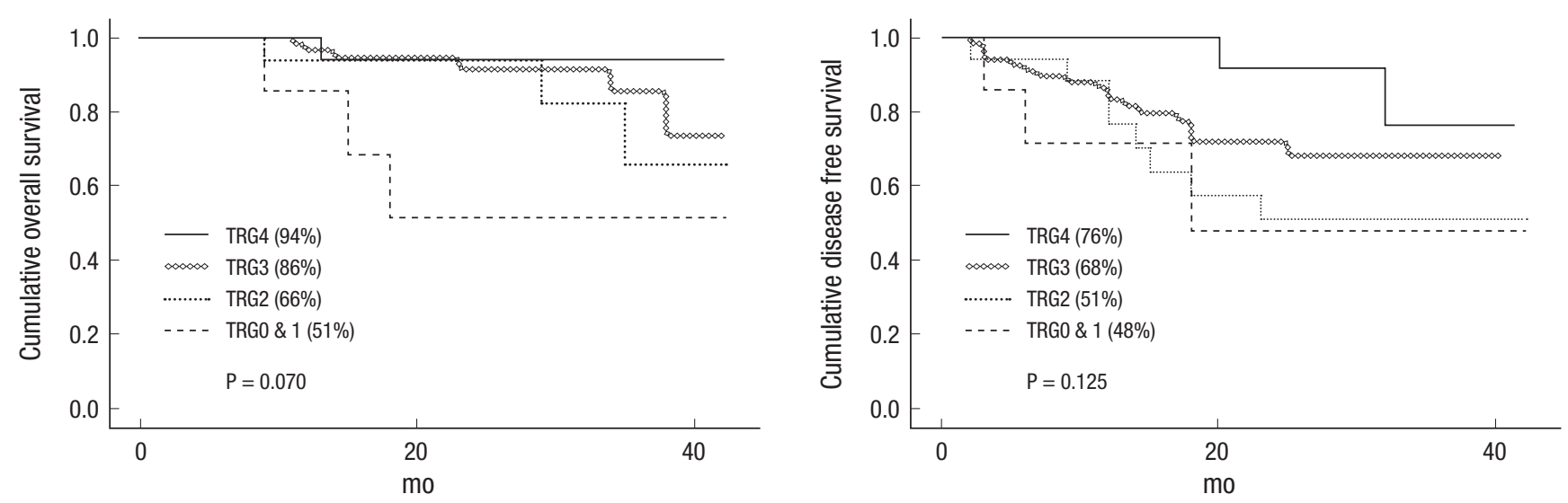

Fig. 2. Cumulative three-year overall survival and three-year disease-free survival between groups according to tumor regression grade (TRG). A comparison of the two shows no statistically significant difference $(\mathrm{P}=0.070, \mathrm{P}=0.125$, Kaplan-Meier Life table analysis). 

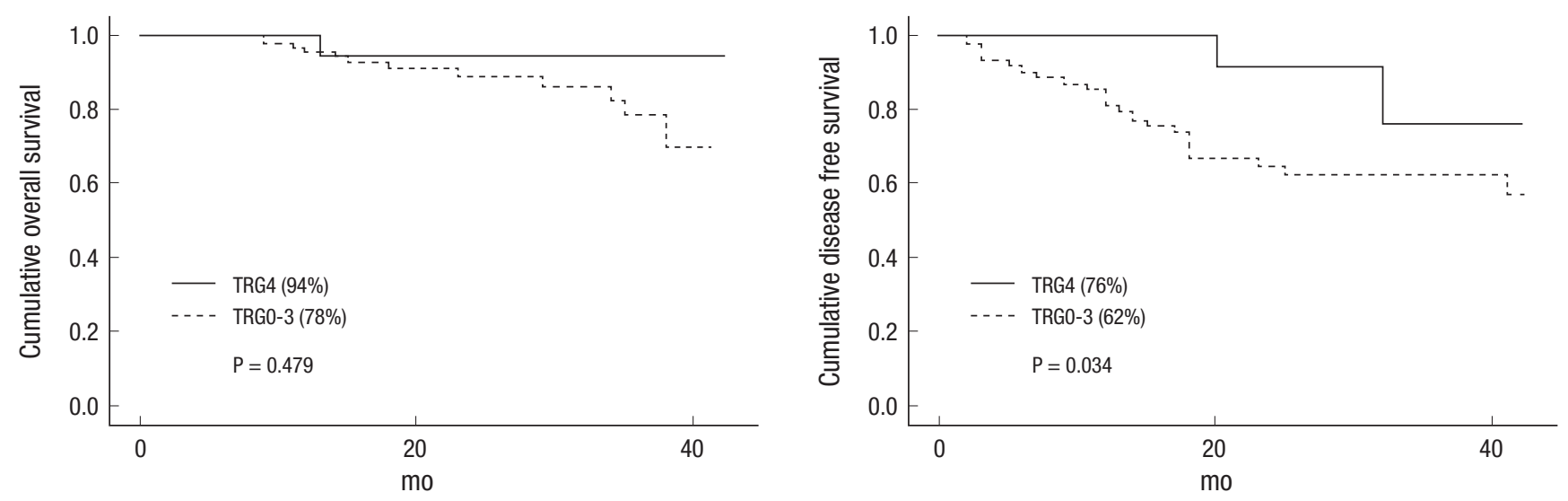

Fig. 3. Cumulative three-year overall survival and three-year disease-free survival (DFS) between the TRG0-3 and the TRG4 groups. The TRG4 group showed a better outcome. The three-year DFS in the TRG4 group showed statistical significance $(\mathrm{P}=0.479, \mathrm{P}=0.034, \mathrm{Kaplan}-\mathrm{Meier}$ Life table analysis).
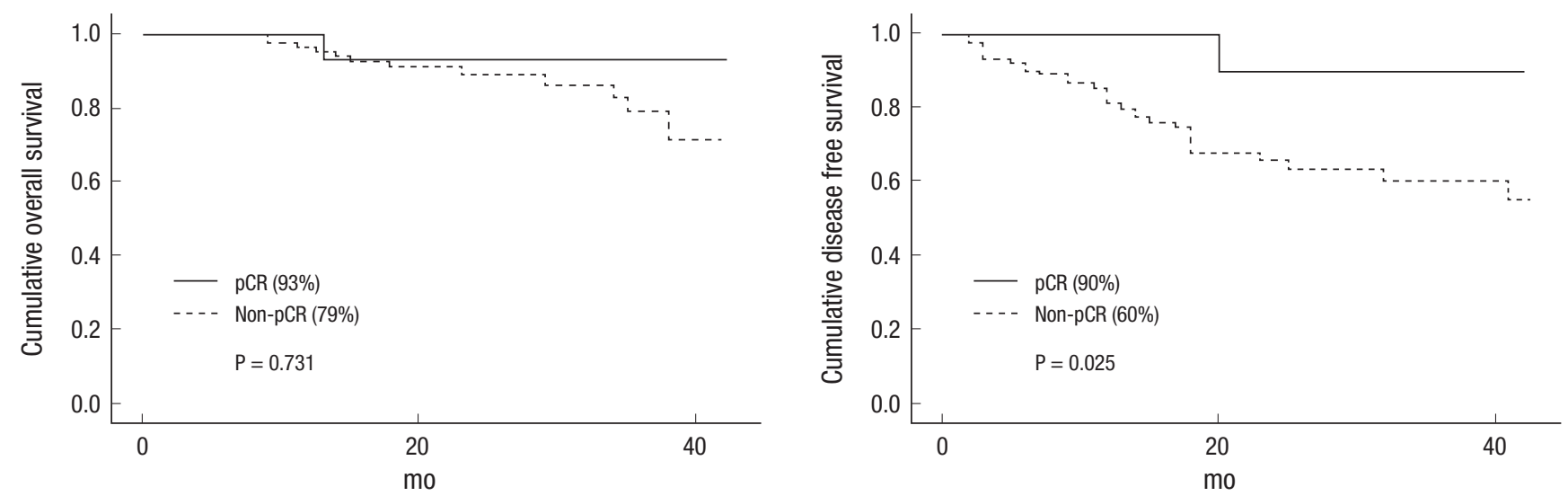

Fig. 4. Cumulative three-year overall survival and three-year disease-free survival (DFS) between the pathologic complete remission (pCR) group and the non-pCR group. The pCR group showed a better outcome. The three-year DFS in the pCR group showed statistical significance $(\mathrm{P}=0.731, \mathrm{P}=0.025$, Kaplan-Meier Life table analysis).

preoperative chemoradiotherapy increased the five-year survival rate to $68-91 \%$ and reduced local recurrence rate to 4 $14 \%[17,18]$.

There are reports that results for rectal cancer patients who had chemoradiotherapy before surgery are affected by prognostic factors: tumor size before surgery, the response rate of the tumor, pathologic downstaging, surgical staging, and pathological findings. These factors are known to affect local tumor control and the survival rate [19-23]. Especially, pathological $\mathrm{N}$ stage is known to be the greatest factor affecting local tumor control and remote tumor control [13]. The downstaging rate caused by preoperative chemoradiotherapy is reported to be $42-84 \%$ [24, 25]. In this study, 64 patients $(60 \%)$ showed downstaging and 26 patients $(24 \%)$ showed $\mathrm{N}$-stage reduction through CCRT.

Factors that can be used to determine the effects of preoperative chemoradiotherapy are the pathologic downstaging, the
OS rate, the DFS rate, and resection margin and pathologic changing degree after CCRT. Although there are no generalized pathological standards, Dworak et al. [12] and Mandard et al. [7] categorizations are widely being used. In this research, Dworak's categorization method was used to divide the tumors into five levels according to the fibrosis rate.

Janjan et al. [20] and Willet et al. [26] reported the preoperative tumor size to be an important factor affecting the TRG. Das [27] insisted that the circumferential extent of the tumor, the tumor's location with respect to the anal verge, and CEA results affected CCRT. In this research, however, we couldn't measure tumor size before CCRT. The location of the tumor and the CEA did not affect the TRG, but perineural invasion and lymphovascular invasion were found to be a significant factors associated with TRG $(\mathrm{P}=0.008, \mathrm{P}=0.032)$.

Theodoropoulos [17] insisted that $\mathrm{T}$ stage reduction and complete remission reduced relapse and increased the DFS. Garcia- 
Aguilar et al. [18] also said that complete remission reduced local relapse and increased the survival rate. From this research, as the TRG increased after CCRT, the OS and the DFS rates increased, and the local recurrence rate decreased $(\mathrm{P}=0.032)$. As a result, the TRG is thought to have a local tumor suppression effect. Among the 89 patients in the TRG0-3 group, 66 patients' (74\%) tumor samples were examined on circumferential resection margins (CRMs), and three patients of them had CRMs of less than $1 \mathrm{~mm}$. In rectal cancer, the CRM is known to be an important prognostic factor twhat affects local relapse and the survival rate [28-30]. However, local relapse was not found during follow-up observation in patients with a CRM less than $1 \mathrm{~mm}$. The CRM was measured by reanalyzing the slides, but we could not do this for every subject patients. More TRG, CRM, local recurrence, and survival research must be done in the future.

Habr-Gama et al. [10] insisted that rectal cancer in stage 0 showed good OS and DFS rates and stage 0 with surgically treated group had more complications than observation only group. He insisted on follow-up observation in the clinically complete remission group. In this research, TRG4 and pCR patients showed better OS and DFS rates. The three-year OS rates of the TRG4 and the pCR groups were $76 \%$ and $90 \%$, respectively. The reason of survival difference between the two groups is that three patients from the TRG4 group were $\mathrm{N}(+)$, and one of them had lung metastasis.

Rodel et al. [13] reported that TRG could be a very important prognostic factor for rectal cancer. Suarez et al. [8] reported that the group with higher TRG showed a better DFS rate and that the TRG was a more significant prognostic factor than pathologic downstaging. However, the TRG cannot be considered as the only prognostic factor that affects rectal cancer patient's survival rate after chemoradiotherapy; $y \mathrm{~T}$ and $\mathrm{yN}$ are also thought to be crucial prognostic factors [31].

Preoperative chemoradiotherapy in rectal cancer reduces the local recurrence rate and increases the long-term survival rate by lowering pathologic tumor stage. The TRG, which shows the effect of chemoradiotherapy, is thought to be an additional prognostic factor that, along with TNM stage, affects the survival rate and the recurrence rate. Finally, standardization of the TRG system and more research on the factors that affect the TRG need to be done.

\section{CONFLICT OF INTEREST}

No potential conflict of interest relevant to this article was reported.

\section{REFERENCES}

1. Shin HR, Jung KW, Won YJ, Park JG; 139 KCCR-affiliated Hospitals. 2002 Annual report of the Korea central cancer registry: based on registered data from 139 hospitals. Cancer Res Treat 2004;36:103-14.

2. Glimelius B. Radiotherapy in rectal cancer. Br Med Bull 2002;64: 141-57.

3. Minsky BD. Is preoperative chemoradiotherapy still the treatment of choice for rectal cancer? J Clin Oncol 2009;27:5115-6.

4. Enker WE. Total mesorectal excision: the new golden standard of surgery for rectal cancer. Ann Med 1997;29:127-33.

5. Minsky BD, Cohen AM, Enker WE, Paty P. Sphincter preservation with preoperative radiation therapy and coloanal anastomosis. Int J Radiat Oncol Biol Phys 1995;31:553-9.

6. Marks G, Mohiuddin M, Masoni L, Montori A. High-dose preoperative radiation therapy as the key to extending sphincter-preservation surgery for cancer of the distal rectum. Surg Oncol Clin North Am 1992;1:71-86.

7. Mandard AM, Dalibard F, Mandard JC, Marnay J, Henry-Amar M, Petiot JF, et al. Pathologic assessment of tumor regression after preoperative chemoradiotherapy of esophageal carcinoma: clinicopathologic correlations. Cancer 1994;73:2680-6.

8. Suarez J, Vera R, Balen E, Gomez M, Arias F, Lera JM, et al. Pathologic response assessed by Mandard grade is a better prognostic factor than down staging for disease-free survival after preoperative radiochemotherapy for advanced rectal cancer. Colorectal Dis 2008;10:563-8.

9. Berger C, de Muret A, Garaud P, Chapet S, Bourlier P, ReynaudBougnoux A, et al. Preoperative radiotherapy (RT) for rectal cancer: predictive factors of tumor downstaging and residual tumor cell density (RTCD): prognostic implications. Int J Radiat Oncol Biol Phys 1997;37:619-27.

10. Habr-Gama A, Perez RO, Nadalin W, Sabbaga J, Ribeiro U Jr, Silva e Sousa AH Jr, et al. Operative versus nonoperative treatment for stage 0 distal rectal cancer following chemoradiation therapy: long-term results. Ann Surg 2004;240:711-7.

11. Huh JW, Kim HR. Postoperative chemotherapy after neoadjuvant chemoradiation and surgery for rectal cancer: is it essential for patients with ypT0-2N0? J Surg Oncol 2009;100:387-91.

12. Dworak O, Keilholz L, Hoffmann A. Pathological features of rectal cancer after preoperative radiochemotherapy. Int J Colorectal Dis 1997;12:19-23.

13. Rodel C, Martus P, Papadoupolos T, Füzesi L, Klimpfinger M, Fietkau $\mathrm{R}$, et al. Prognostic significance of tumor regression after preoperative chemoradiotherapy for rectal cancer. J Clin Oncol. 2005;23:8688-96.

14. Heald RJ, Husband EM, Ryall RD. The mesorectum in rectal cancer surgery: the clue to pelvic recurrence? Br J Surg 1982;69: 613-6.

15. Heald RJ, Moran BJ, Ryall RD, Sexton R, MacFarlane JK. Rectal cancer: the Basingstoke experience of total mesorectal excision, 1978-1997. Arch Surg 1998;133:894-9.

16. Improved survival with preoperative radiotherapy in resectable rectal cancer. Swedish Rectal Cancer Trial. N Engl J Med 1997; 336:980-7. 
17. Theodoropoulos G, Wise WE, Padmanabhan A, Kerner BA, Taylor CW, Aguilar PS, et al. T-level downstaging and complete pathologic response after preoperative chemoradiation for advanced rectal cancer result in decreased recurrence and improved diseasefree survival. Dis Colon Rectum 2002;45:895-903.

18. Garcja-Aguilar J, Hernandez de Anda E, Sirivongs P, Lee SH, Madoff RD, Rothenberger DA. A pathologic complete response to preoperative chemoradiation is associated with lower local recurrence and improved survival in rectal cancer patients treated by mesorectal excision. Dis Colon Rectum 2003;46:298-304.

19. Moore HG, Gittleman AE, Minsky BD, Wong D, Paty PB, Weiser $\mathrm{M}$, et al. Rate of pathologic complete response with increased interval between preoperative combined modality therapy and rectal cancer resection. Dis Colon Rectum 2004;47:279-86.

20. Janjan NA, Khoo VS, Abbruzzese J, Pazdur R, Dubrow R, Cleary $\mathrm{KR}$, et al. Tumor downstaging and sphincter preservation with preoperative chemoradiation in locally advanced rectal cancer: the M. D. Anderson Cancer Center experience. Int J Radiat Oncol Biol Phys 1999;44:1027-38.

21. Chan AK, Wong A, Jenken D, Heine J, Buie D, Johnson D. Posttreatment TNM staging is a prognostic indicator of survival and recurrence in tethered or fixed rectal carcinoma after preoperative chemotherapy and radiotherapy. Int J Radiat Oncol Biol Phys 2005;61:665-77.

22. Supiot S, Bennouna J, Rio E, Meurette G, Bardet E, Buecher B, et al. Negative influence of delayed surgery on survival after preoperative radiotherapy in rectal cancer. Colorectal Dis 2006;8:430-5.

23. Lindebjerg J, Spindler KL, Ploen J, Jakobsen A. The prognostic value of lymph node metastases and tumour regression grade in rectal cancer patients treated with long-course preoperative chemoradiotherapy. Colorectal Dis 2009;11:264-9.
24. Kim JS, Kim JS, Cho MJ, Song KS, Yoon WH. Preoperative chemoradiation using oral capecitabine in locally advanced rectal cancer. Int J Radiat Oncol Biol Phys 2002;54:403-8.

25. Rullier E, Goffre B, Bonnel C, Zerbib F, Caudry M, Saric J. Preoperative radiochemotherapy and sphincter-saving resection for T3 carcinomas of the lower third of the rectum. Ann Surg 2001; 234:633-40.

26. Willett CG, Warland G, Coen J, Shellito PC, Compton CC. Rectal cancer: the influence of tumor proliferation on response to preoperative irradiation. Int J Radiat Oncol Biol Phys 1995;32: 57-61.

27. Das P, Skibber JM, Rodriguez-Bigas MA, Feig BW, Chang GJ, Wolff RA, et al. Predictors of tumor response and downstaging in patients who receive preoperative chemoradiation for rectal cancer. Cancer 2007;109:1750-5.

28. Luna-Perez P, Bustos-Cholico E, Alvarado I, Maffuz A, RodriguezRamirez S, Gutierrez de la Barrera M, et al. Prognostic significance of circumferential margin involvement in rectal adenocarcinoma treated with preoperative chemoradiotherapy and low anterior resection. J Surg Oncol 2005;90:20-5.

29. Nagtegaal ID, Quirke P. What is the role for the circumferential margin in the modern treatment of rectal cancer? J Clin Oncol 2008;26:303-12.

30. Wibe A, Rendedal PR, Svensson E, Norstein J, Eide TJ, Myrvold $\mathrm{HE}$, et al. Prognostic significance of the circumferential resection margin following total mesorectal excision for rectal cancer. $\mathrm{Br} J$ Surg 2002;89:327-34.

31. Chapet O, Romestaing P, Mornex F, Souquet JC, Favrel V, Ardiet JM, et al. Preoperative radiotherapy for rectal adenocarcinoma: Which are strong prognostic factors? Int J Radiat Oncol Biol Phys 2005;61:1371-7. 